\title{
MicroRNA-146a constrains multiple parameters of intestinal immunity and increases susceptibility to DSS colitis
}

\author{
Marah C. Runtsch ${ }^{1}$, Ruozhen Hu${ }^{1}$, Margaret Alexander ${ }^{1}$, Jared Wallace ${ }^{1}$, Dominique \\ Kagele $^{1}{ }^{\text {, Charisse Petersen }}{ }^{1}$, John F. Valentine ${ }^{4}$, Noah C. Welker ${ }^{2}$, Mary P. Bronner ${ }^{2}$, \\ Xinjian Chen ${ }^{1}$, Daniel P. Smith ${ }^{3}$, Nadim J. Ajami ${ }^{3}$, Joseph F. Petrosino ${ }^{3}$, June L. \\ Round $^{1}$ and Ryan M. O'Connell ${ }^{1}$ \\ ${ }^{1}$ Department of Pathology, University of Utah, Salt Lake City, UT, USA \\ 2 Department of Pathology, University of Utah and ARUP Laboratories, Salt Lake City, UT, USA \\ ${ }^{3}$ The Alkek Center for Metagenomics and Microbiome Research, Department of Molecular Virology and Microbiology, Baylor \\ College of Medicine, Houston, TX, USA \\ ${ }^{4}$ Department of Medicine, Division of Gastroenterology, University of Utah, Salt Lake City, UT, USA \\ Correspondence to: Ryan M. O'Connell, email: ryan.oconnell@path.utah.edu
}

Keywords: miRNA, miR-146a, intestine, microbiota, colitis

Received: August 14, $2015 \quad$ Accepted: August 22, $2015 \quad$ Published: September 10, 2015

This is an open-access article distributed under the terms of the Creative Commons Attribution License, which permits unrestricted use, distribution, and reproduction in any medium, provided the original author and source are credited.

\section{ABSTRACT}

Host-microbial interactions within the mammalian intestines must be properly regulated in order to promote host health and limit disease. Because the microbiota provide constant immunological signals to intestinal tissues, a variety of regulatory mechanisms have evolved to ensure proper immune responses to maintain homeostasis. However, many of the genes that comprise these regulatory pathways, including immune-modulating microRNAs (miRNAs), have not yet been identified or studied in the context of intestinal homeostasis. Here, we investigated the role of microRNA-146a (miR-146a) in regulating intestinal immunity and barrier function and found that this miRNA is expressed in a variety of gut tissues in adult mice. By comparing intestinal gene expression in WT and miR-146a-/- mice, we demonstrate that $\mathbf{m i R - 1 4 6 a}$ represses a subset of gut barrier and inflammatory genes all within a network of immune-related signaling pathways. We also found that miR-146a restricts the expansion of intestinal $T$ cell populations, including Th17, Tregs, and Tfh cells. GC B cells, Tfh ICOS expression, and the production of luminal IgA were also reduced by miR-146a in the gut. Consistent with an enhanced intestinal barrier, we found that miR-146a-/- mice are resistant to DSS-induced colitis, a model of Ulcerative Colitis (UC), and this correlated with elevated colonic miR-146a expression in human UC patients. Taken together, our data describe a role for miR-146a in constraining intestinal barrier function, a process that alters gut homeostasis and enhances at least some forms of intestinal disease in mice.

\section{INTRODUCTION}

The mammalian intestine contains a variety of cell types that coordinate complex processes in order to maintain a barrier between host tissues and resident microbes within the gastrointestinal (GI) tract. An appropriate balance of pro-inflammatory responses to support the barrier, along with mechanisms to ensure the proper degree of immunotolerance, must be achieved to receive the benefits provided by the microbiota while continuing to protect the host from microbial invasion. In order to maintain homeostasis, immunological processes within the gut require proper modulation, as dysregulation has been shown to cause infection, dysbiosis, cancer, and/ or autoimmunity [1-3]. Among these unwanted outcomes is inflammatory bowel disease (IBD), which manifests itself as Crohn's Disease (CD) and Ulcerative Colitis (UC) in human patients. IBD affects millions of people around 
the world, producing a substantial burden on healthcare systems [4]. Identifying risk factors, providing an accurate prognosis, and effectively treating this condition all remain challenging due the complexity of the environmental, genetic, and cellular factors involved in the development of IBD. However, these may be improved as we continue to identify and characterize regulatory mechanisms at play within the gut.

A variety of cell types are involved in promoting intestinal homeostasis, and are made up of both hematopoietic-derived leukocytes and cells of the nonhematopoietic lineage, including intestinal epithelial cells (IECs). Among the immune cells involved, specific $\mathrm{T}$ cell lineages play a large role in influencing gut responses. Regulatory $\mathrm{T}$ cells (Tregs) are required to maintain tolerance and downregulate gut immune responses [1, 5]; $\mathrm{T}$ follicular helper ( $\mathrm{Tfh}$ ) cells interact with $\mathrm{B}$ cells in the intestine to help produce antigenspecific antibodies, including $\operatorname{IgA}$, against intestinal microbes to maintain barrier [6-8]; and Th1 and Th17 cells produce specific cytokines to coordinate responses against invading microbes $[9,10]$. Th1 cells have been associated with Crohn's Disease in humans, while Th17 cells are implicated both in intestinal tissue damage and in intestinal tissue repair and homeostasis in other contexts [9-12]. The non-hematopoietic derived IECs maintain homeostasis by producing mucus, antimicrobial peptides, and other factors that promote tissue repair, tight junctions, and bacterial targeting $[13,14]$. Both T lymphocytes and IECs express cell surface receptors, such as TLRs, that are able to recognize microbial cues and initiate appropriate responses $[13,15]$. Downstream from TLRs, signaling through MyD88 and ultimately NF- $\kappa \mathrm{B}$ is critical for the proper function of cells within the gut, as disruption of this pathway results in intestinal disease [16-19]. Thus, the proper control of TLR/ NF- $\kappa \mathrm{B}$ signaling is essential to overall gut health.

MicroRNAs (miRNAs) are short, non-protein coding RNAs that have been shown to play significant roles in regulating cellular processes within the immune system. miRNAs function to repress their target mRNA genes by binding the 3'-UTR of targets in a mature, RNA-induced silencing complex (RISC)-bound form. Target genes are downregulated approximately 1.5 to 4 fold by miRNAs [20], in such a way that these noncoding RNAs modulate cellular processes in order to maintain equilibrium and/ or stability [20-23]. This includes miRNAs within the intestine [24], such as miR-143/145, which have recently been shown to promote IEC regeneration during stress [25]. Among important immune system-related miRNAs is microRNA-146a (miR-146a), which is largely expressed within leukocytes and is induced by pattern recognition receptors and cytokine receptors that activate NFאB [26, 27]. Once induced, miR-146a acts as a negative feedback regulator by targeting TNF receptor-associated factor 6 (Traf6) and IL-1 receptor associated kinase 1 (Irak1), both of which link MyD88 to NFאB signaling [23, 28-30]. miR-146a has also been shown to target Signal Transducer and Activator of Transcription 1 (Stat1) in T cells [31]. Recently, Inducible T-cell costimulator (ICOS), as well as other mRNAs involved in Tfh cell and germinal center biology, were shown to be targets of miR-146a [32]. Through these mechanisms, miR-146a is able to prevent excessive inflammation in response to microbial cues.

Although miR-146a plays a protective antiinflammatory role within systemic compartments, such as the bone marrow, spleen, lymph nodes and joints $[23,27,29,33]$, its relevance within the adult GI tract remains unclear. This miRNA has been implicated in regulating pathways of intestinal disease [30, 34, 35], although studies with miR-146a-/- mice have not yet been performed in this context. Intestinal immunity and barrier function involve unique cell types and processes that are not found or do not occur in other tissues and are in place to regulate the constant exposure to microbial signals that come from resident intestinal commensal organisms. Thus, we investigated whether miR-146a also plays a host-protective role in this context. We report that miR-146a is expressed in the intestines under the steady state and functions to downregulate a subset of genes and immune cells involved in intestinal barrier function. miR-146a-/- mice displayed an altered microbiota and, surprisingly, were more protected from DSS-induced colitis compared to their WT counterparts. In vivo bone marrow reconstitutions demonstrated a contribution by hematopoietic-expressed miR-146a in mediating colitis severity. Consistent with a negative role in intestinal disease, miR-146a was elevated in a cohort of patients with IBD compared to healthy controls. Altogether, through its negative regulation of barrier function, miR146a limits intestinal health during certain types of stress responses.

\section{RESULTS}

\section{miR-146a is expressed within the intestines}

We characterized the expression profile of miR146 a within gut tissues to begin to identify the cell types in which it may be functioning within the GI tract. miR146a expression has been well-characterized within hematopoietic cells of the blood, spleen, and bone marrow [36], but its expression within intestinal tissues is not well defined. We found that mature miR-146a is expressed in both the distal colon (C) and in the small intestine (SI) (specifically in the ileum) (Figure 1a). As a control, miR146 a was not detected in intestinal tissues from miR146a-/- mice. Furthermore, miR-146a expression was compared between small intestinal tissues and adjacent Peyer's Patches (PP), and its levels were similar in both 
compartments (Figure 1b), indicating that miR-146a levels are not increased in the lymphocyte-rich Peyer's Patch. Because miR-146a has been shown to be induced

a.

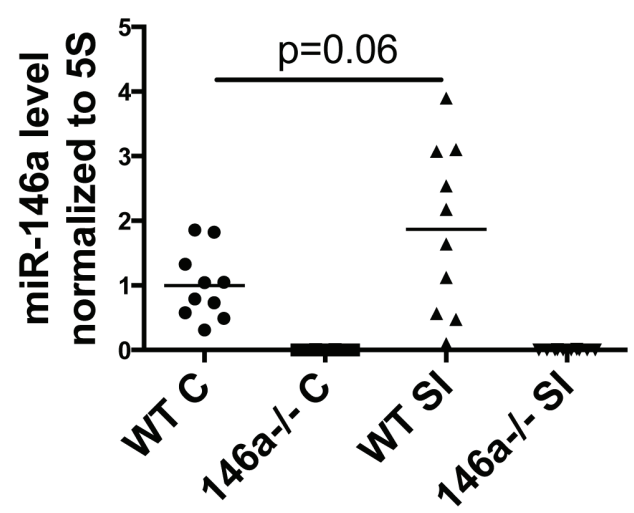

b.

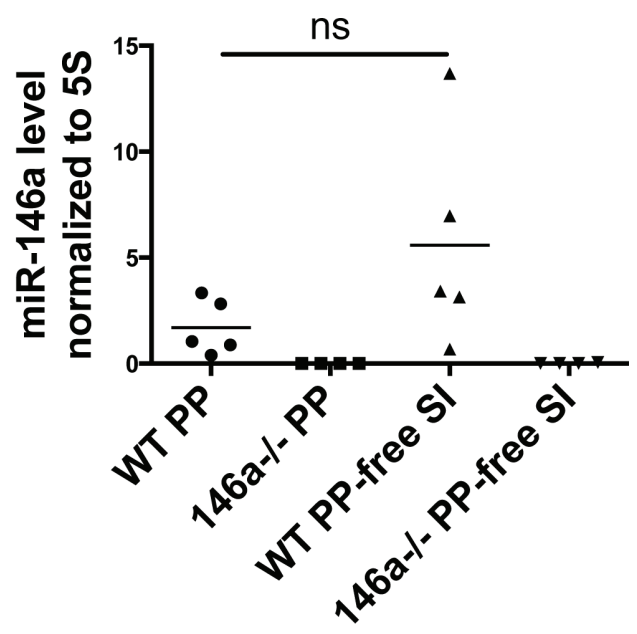

C.

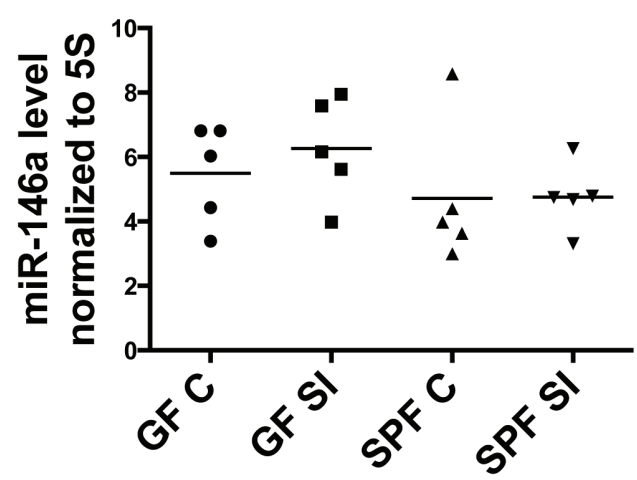

Figure 1: miR-146a is expressed within the intestinal tract. Mature miR-146a RNA expression was measured in whole colonic (C) and ileal (SI) tissue of WT C57BL/6 and miR146a-/- mice via qRT-PCR a. RNA was extracted from whole WT and miR-146a-/- Peyer's Patches (PP) and an adjacent piece of small intestinal tissue lacking a PP, followed by qRT-PCR for mature miR-146a expression b. Mature miR-146a expression levels were measured in colons (C) and small intestines (SI) of germ-free (GF) and specific pathogen free (SPF) C57BL/6 mice using qRT-PCR c. All miR-146a levels were normalized to $5 \mathrm{~S}$ rRNA; $n=10$ (a), $n=5$ (b), $n=5$ (c). by TLR/NFkB signaling [26], which can be activated by the intestinal microbiota, we examined mature miR-146a expression in the intestines of germ-free (GF) versus specific pathogen-free (SPF) mice. Equivalent expression within the small intestines and colon was observed when comparing GF and SPF mice, indicating that the presence of the microbiota has little impact on miR-146a levels in the gut (Figure 1c). To determine expression levels of miR-146a in hematopoietic versus nonhematopoietic cells of the intestines, we performed FACS-sorting of CD45 and CD45 cells from mouse colons and small intestines. miR-146a was expressed within $\mathrm{CD}^{+} 5^{+}$cells of the small intestine and colon, while much lower expression was observed in CD45 cells from these tissues (Supplementary Figure 1a and 1b). Altogether, miR-146a is expressed in a variety of intestinal tissues, primarily within cells of the hematopoietic lineage, and this occurs in a microbiotaindependent manner.

\section{miR-146a represses barrier gene expression in the intestines}

To begin determining the functional role of miR146a within the intestines, RNA was collected from the distal portions of the colon and ileum of the small intestines of WT and miR-146a-/- mice, and RNA-seq was performed to examine gene expression changes in an unbiased manner. A majority of the significant alterations in gene expression occurred within the small intestine (Supplementary Figure 2a), while substantially fewer differences were seen within the colon (Supplementary Figure 2b). In the small intestine, 289 genes were upregulated and 77 genes were downregulated greater than two fold (FDR > 10) within the small intestines of miR-146a-/- mice compared with equivalent tissues from WT mice (Supplementary Figure 2a). Among the top upregulated genes in miR-146a-/- small intestines were members of the C-type lectin antimicrobial peptide family Reg3: Reg3 $\alpha$, Reg3 $\beta$, and Reg3 $\gamma$ (Figure 2a), which are expressed by IECs and function to kill grampositive bacteria [37-39]. Reg3 proteins have been shown to play an essential role in intestinal barrier function and protection from colitis [40], indicating that miR-146a-/mice have enhanced gut barrier function. Another highly upregulated gene in the miR-146a-/- small intestine was serum amyloid a 1 (Saal), an acute phase, inflammationpromoting gene [41] that has antibacterial effects and is required for protection from colitis [42]. miR-146a-/small intestines also had higher expression of a number of genes that produce intestinal mucus, including Muc3, Muc4, and Muc13[43]. Other important intestinal barrier genes, including interferon response genes RNaseL, Oasl1, Nos2 and Ifit1 [44-46], as well as intestinal cell adhesion molecules Ceacam1, Ceacam20, Ceacam18, and Epcam, were expressed at higher levels in miR-146a-/- 
a.
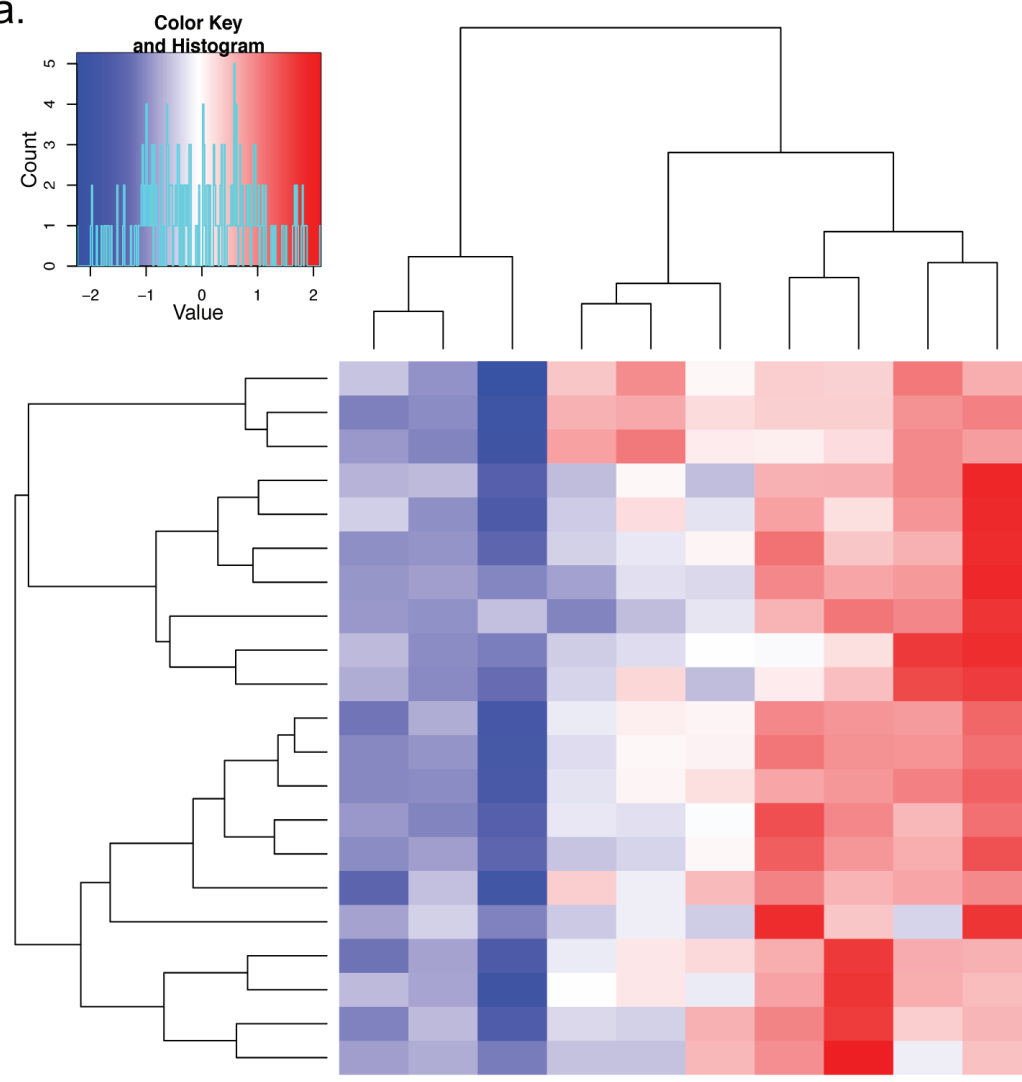

Legend:

$\checkmark$ Secreted

antimicrobial

peptide

$\rightarrow$ Cell surface/

adhesion

molecule

$\varnothing$ Interferon

response gene

Epcam

Gpr128 $\odot \quad$ Cytokine/

$\mathrm{Ccl} 25$

Oasl1

Ceacam18 Other immune-

Reg3b

Saa1 $\rightarrow$

Il18bp $\odot$

Ifit1

Ido1

Ceacam1

Muc3 0

Muc13

Reg3a

Reg3g

Muc4 0

II18

Rnasel

Ceacam20

$\mathrm{Cd} 38 \rightarrow$

Nos2

$\odot \begin{aligned} & \text { Mucus } \\ & \text { component }\end{aligned}$

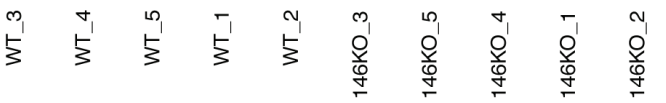

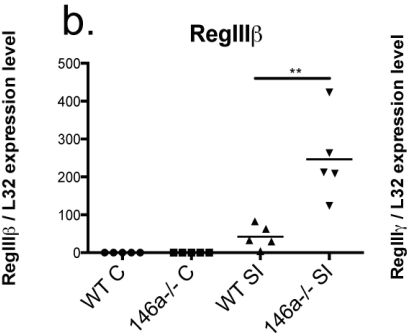

C.

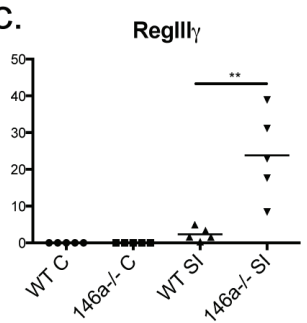

g.

f.

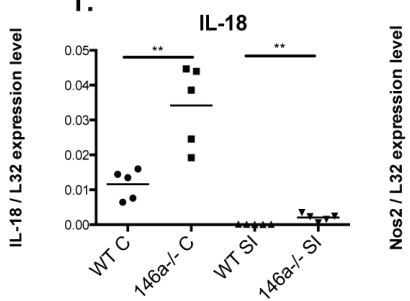

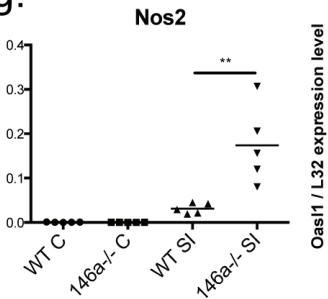
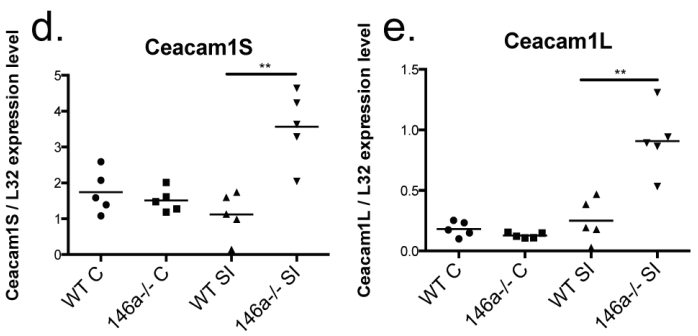

h.

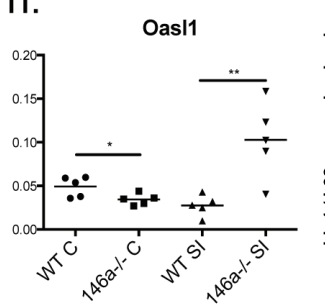

i.

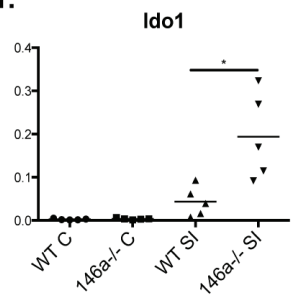

Figure 2: miR-146a regulates expression of genes important for intestinal barrier and homeostasis. RNA-seq was performed on a section of ileal tissue of WT C57BL/6 and miR-146a-/- mice. Heat map indicates fold change in gene expression of selected intestinal barrier genes comparing miR-146a-/- mice with WT, $p<0.05$, Phred-transformed FDR $>10$. Genes are categorized by their known functions within the intestine and/or immune system (antimicrobial peptide, cell surface/adhesion, interferon response, cytokine/ chemokine, immune-related, and mucus component) a. Select genes upregulated in miR-146a-/- small intestines and colons, including Reg3 $\beta$ b., Reg3 $\gamma$ c., Ceacam1S d., Ceacam1L e., IL-18 f., Nos2 g., Oas11 h., and Ido1 i.; were confirmed via qRT-PCR normalized to L32. $n=5(\mathrm{a}), n=5(\mathrm{~b}-\mathrm{i})$. 
small intestines compared to WT [47-49]. Futhermore, a subset of genes that make up epithelial cell junctions and enhance the intestinal barrier, including claudins, occludin, and e-Cadherin [50], were modestly upregulated in mice lacking miR-146a (Supplementary Figure 3b). Also of note, the cytokine IL-18 and regulator protein IL18bp, in addition to the enzyme Ido1, were at higher levels in the absence of miR-146a. Increased IL-18 [51, 52] and Ido1 [53] levels have been shown to play a protective role in mice during experimental colitis. Several of these gene expression changes within the small intestine were confirmed via qRT-PCR including Reg $3 \beta, \operatorname{Reg} 3 \gamma$, Ceacam1 (short and long isoforms), IL-18, Nos2, Oas11, and Ido1 (Figure 2b-i). Also of interest, IL-18 expression was found to be significantly upregulated in the colons of miR-146a-/- versus WT mice (Figure 2f). Using Targetscan and miRTarBase, 18 predicted and confirmed miR-146a targets were found to be derepressed within whole ileal tissues of miR-146a-/- mice compared with WT controls (Supplementary Figure 3a). Derepression of the confirmed miR-146a target NUMB correlated with decreased expression of downstream Shh signaling genes (Supplementary Figure 3c), which can play a role in IBD pathology [35]. Altogether, these data demonstrate that miR-146a functions to repress genes involved in intestinal barrier function and immunoprotective inflammation.

In order to identify signaling pathways that miR146a may be directly regulating within the small intestine, we performed a pathway analysis of the RNA-seq data using the IPA software program from Ingenuity. Among the top upstream regulators predicted to be activated in the absence of miR-146a were the cytokines IL-18 and IL-22; the IL-1R, IL-18R and TLR adaptor protein MyD88; the

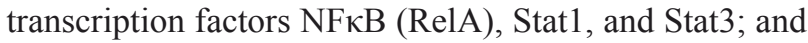
type I and II interferons IFN $\beta$ and IFN $\gamma$ (Supplementary Figure $4 \mathrm{a})$. This predicted enhancement in signaling by MyD88 and NF- $\mathrm{BB}$, as well as enhanced interferon and Stat1 signaling, is consistent with previous data demonstrating that miR-146a can directly repress Traf6 and Irak1 (both downstream from MyD88 and upstream of NFкB) [26,27,29] as well as Stat1 (IFN pathway) [31]. Further, Ingenuity predicted that miR-146a-/- mice should be resistant to inflammatory bowel disease (IBD) and colitis (Supplementary Figure 4b). Based upon these results and on previous findings that MyD88 [16, $18,38,54]$ and downstream signals promote intestinal barrier function, our data suggest that miR-146a-/- mice have enhanced barrier function within their intestinal tract through a mechanism involving enhanced MyD88 signaling.

\section{miR-146a constrains Th17 and Treg populations within the lamina propria}

In addition to the barrier gene products described above, leukocytes are also critical regulators of intestinal barrier function and participate in the regulation of these genes. Thus, we examined immune cell populations of the small intestinal and colonic lamina propria (LP), comparing WT to miR-146a-/- mice. Few differences were observed in LP myeloid $\left(\mathrm{CD} 11 b^{+}\right)$and B cell $\left(\mathrm{B} 220^{+}\right)$proportions and numbers when comparing WT and miR-146a-/- mice (Supplementary Figure 5b, 5c, 5e, and 5f). However, miR-146a-/- mice had an expansion of $\mathrm{CD}^{+} \mathrm{T}$ cells within the small intestinal and colonic LP (Supplementary Figure 5a and 5d). Upon examination of specific $\mathrm{CD}^{+}$helper $\mathrm{T}$ cell populations, we observed an increase in Th17 and Treg cells in miR-146a-/- mice, both in small intestinal (Figure $3 \mathrm{a}$ and $3 \mathrm{~b}$ ) and colonic (Figure $3 c$ and $3 d)$ LP. Altogether, these results demonstrate that miR-146a plays a role in restricting $\mathrm{CD}^{+}$helper $\mathrm{T}$ cell populations within the intestinal lamina propria, primarily of the Th17 and Treg cell subsets. These cell subsets have previously reported functions in intestinal barrier and tolerance $[5,11,12]$, including the regulation of several barrier genes, indicating that miR-146a is playing an immunomodulatory role to shape the intestinal immune landscape.

\section{miR-146a constrains germinal center reactions in the Peyer's Patch}

In addition to the LP, T lymphocytes of gutassociated lymphoid tissues such as Peyer's Patches (PP) are also critical regulators of intestinal barrier function. In particular, $\mathrm{T}$ follicular helper ( $\mathrm{Tfh}$ ) cells and their interactions with germinal center (GC) B cells within the intestinal PP are essential to produce $\operatorname{IgA}$ and maintain intestinal homeostasis [55]. Because miR-146a plays a role in Tfh and GC B cell accumulation in extra-intestinal tissues [32,56] and is expressed within the PP (Figure 1b) we examined lymphocyte populations within this gutassociated lymphoid tissue. miR-146a-/- mice displayed an expansion in both the percentage and total number of PD- $1^{+} \mathrm{CXCR}^{+}$Tfh cells within the PP compared with WT mice (Figure 4a). Tfh cells interact with GC B cells within the PP to promote antigen-specific IgA responses [57]. Accordingly, the observed expansion of Tfh cells corresponded with an increase in $\mathrm{GL}^{+} \mathrm{FAS}^{+} \mathrm{GC}$ B cells in the PP (Figure 4b). Inducible costimulator (ICOS) expression on Tfh cells is essential for their differentiation and function during germinal center responses [58] and is a direct target of miR-146a [32]. Within the PP, we observed a significant increase in ICOS expression (MFI) on total $\mathrm{CD}^{+} \mathrm{T}$ cells and on $\mathrm{Tfh}$ cells upon loss of miR146a (Figure 4c), consistent with elevated Tfh, GC B 


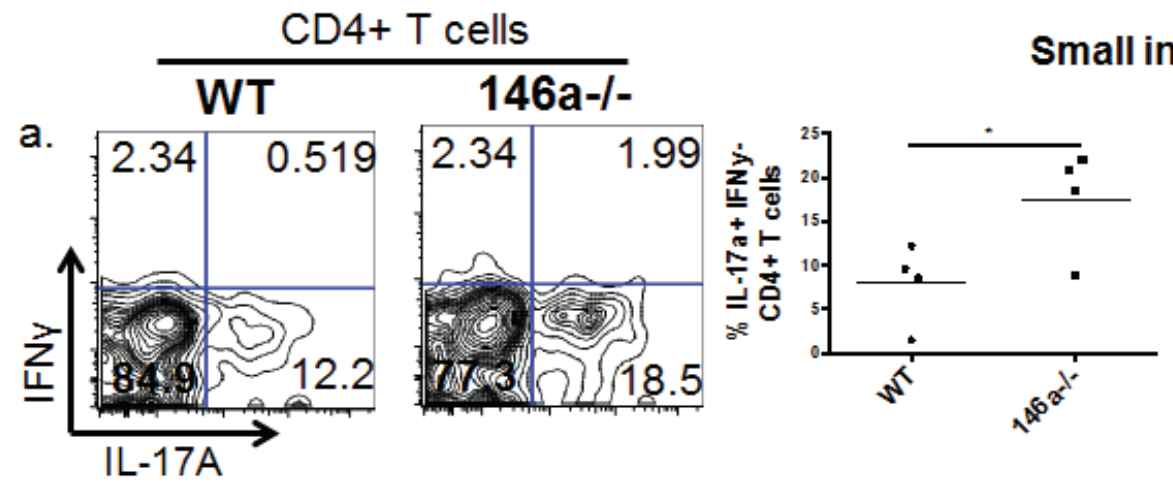

Small intestine LP
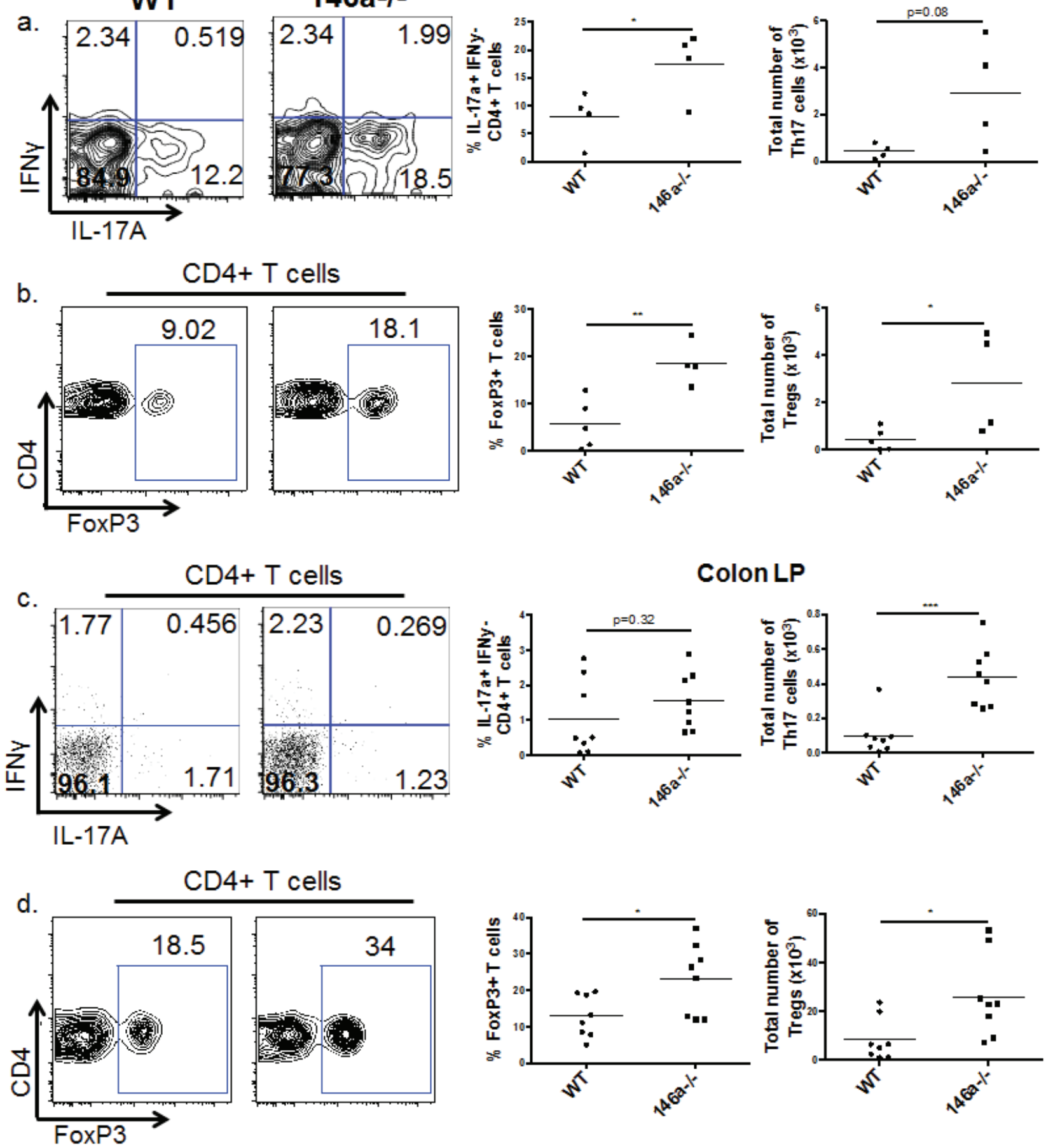

Figure 3: miR-146a constrains Th17 and Treg populations in the lamina propria. Lymphocytes were isolated from the small intestinal lamina propria, and flow cytometry was utilized to examine immune cell populations within this tissue. Displayed are representative flow plots (Wt on the left and miR-146a-/- on the right), percentages, and total numbers of IL-17A ${ }^{+}$IFN $\gamma^{-}$(Th17) $\mathrm{CD}^{+}$ $\mathrm{CD} 3 \mathrm{e}^{+} \mathrm{T}$ cells within the small intestine LP. All populations were first gated on lymphocytes using the $\mathrm{FSC} / \mathrm{SSC}$ gate, then on CD3e $\mathrm{e}^{+} 4^{+}$ cells, followed by the IL-17A and IFN $\gamma$ gating shown a. Representative flow plots, percentages, and total numbers of FoxP3 ${ }^{+}$(Treg) $\mathrm{CD}^{+}$ $\mathrm{CD} 3 \mathrm{e}^{+} \mathrm{T}$ cells within the small intestine LP. All populations were first gated on lymphocytes using the $\mathrm{FSC} / \mathrm{SSC}$ gate, then on CD3e $\mathrm{CD}^{+}$ cells, followed by the FoxP3 ${ }^{+}$gating shown b. Displayed are representative flow plots, percentages, and total numbers of IL-17A ${ }^{+}$IFN $\gamma^{-}$ (Th17) $\mathrm{CD}^{+} \mathrm{CD} 3 \mathrm{e}^{+} \mathrm{T}$ cells within the colonic LP. All populations were first gated on lymphocytes using the FSC/SSC gate, then on CD3e $\mathrm{S}^{+}$ $\mathrm{CD}^{+}$cells, followed by the IL-17A and IFN $\gamma$ gating shown c. Representative flow plots, percentages, and total numbers of FoxP3 ${ }^{+}($Treg) $\mathrm{CD}^{+} \mathrm{CD}^{-} \mathrm{e}^{+} \mathrm{T}$ cells within the colonic LP. All populations were first gated on lymphocytes using the $\mathrm{FSC} / \mathrm{SSC}$ gate, then on CD3e $\mathrm{CD}^{+}$ cells, followed by the FoxP3 ${ }^{+}$gating shown d. $n=5$ (WT) and 4 (miR-146a-/-) (a, b), $n=8$ (c, d). 

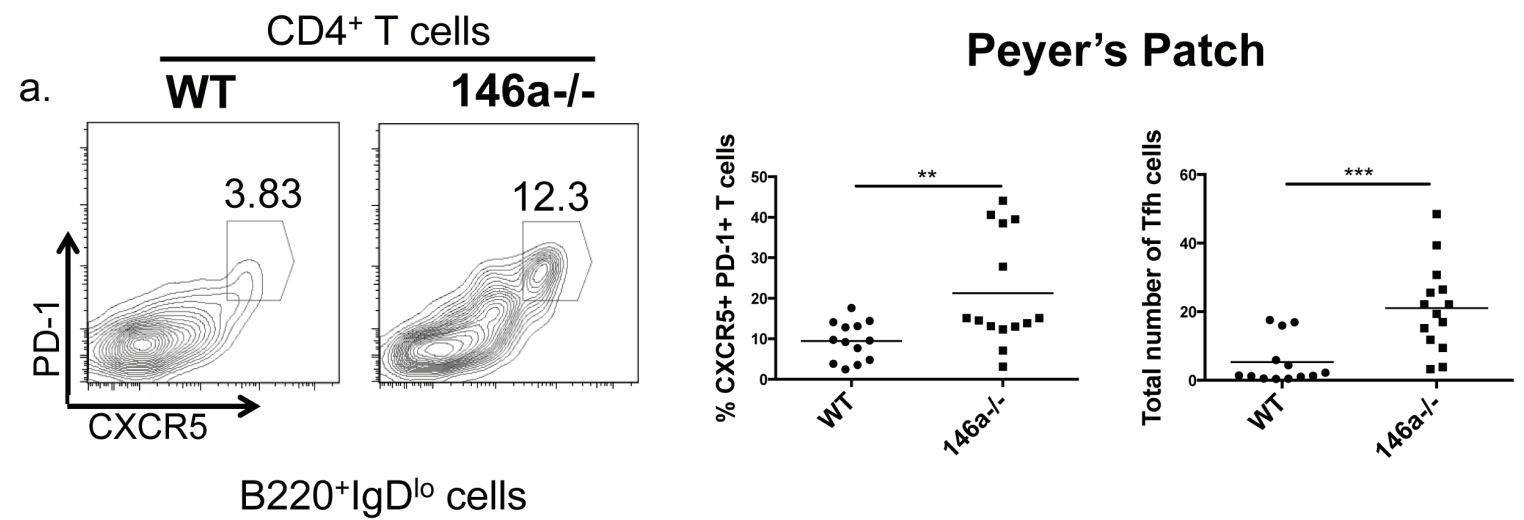

b.

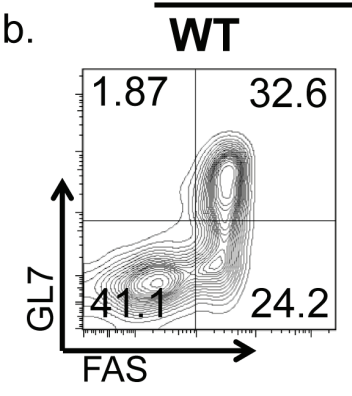

146a-/-
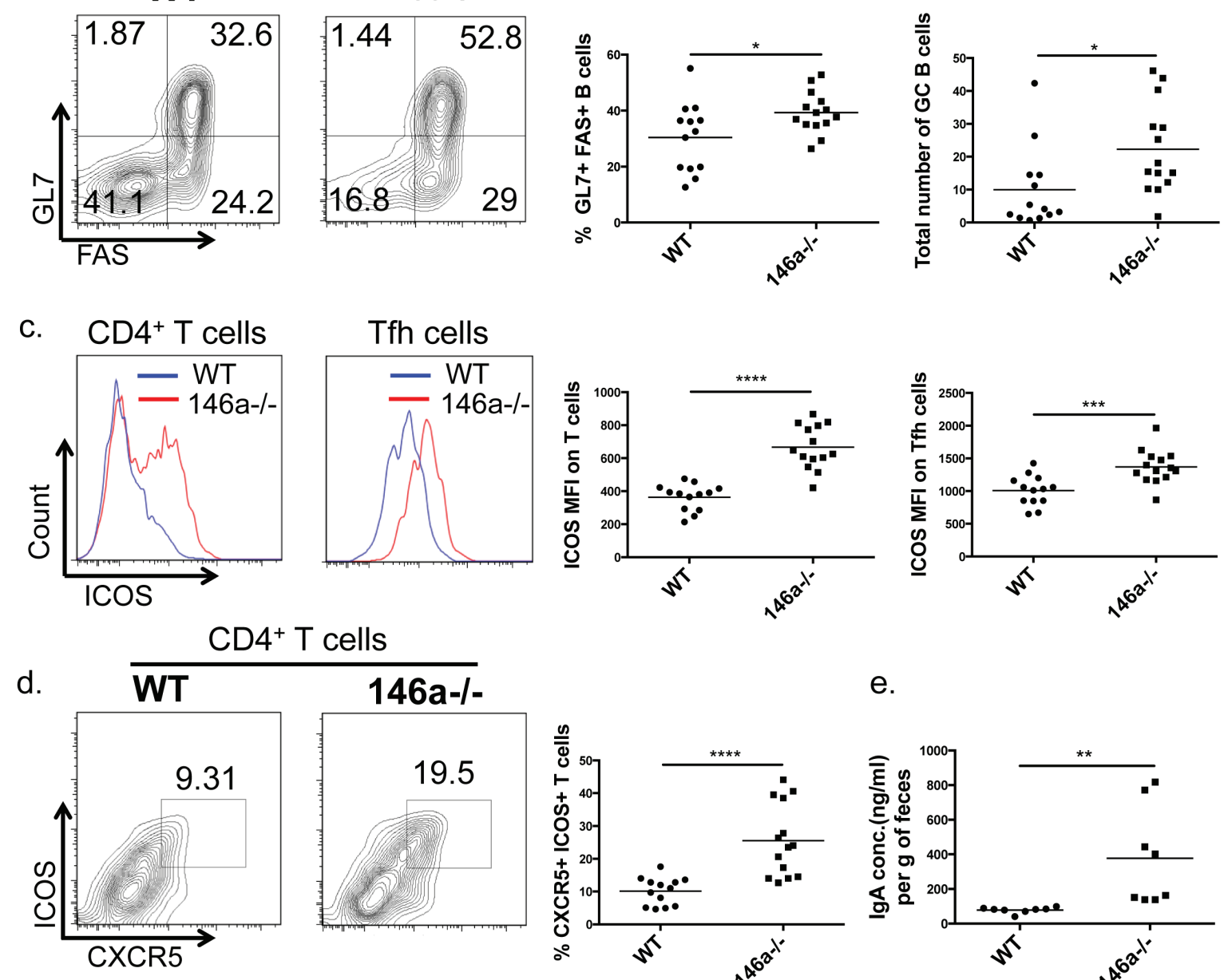

$146 a-/-$

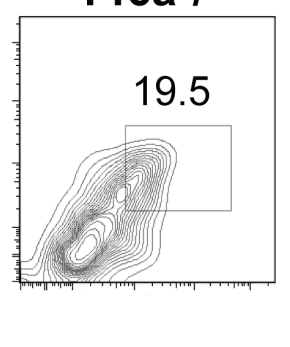

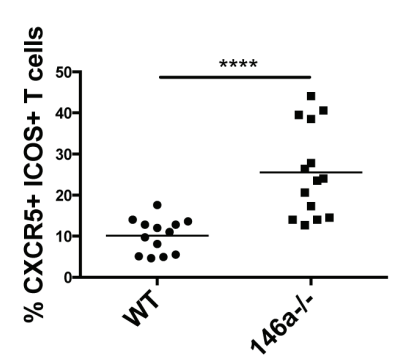

e.

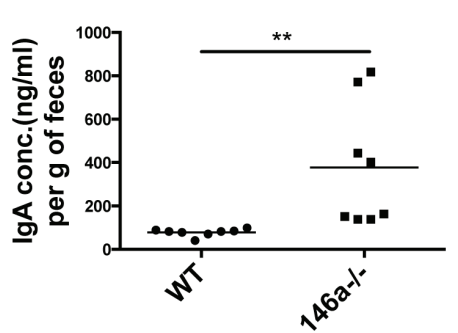

Figure 4: miR-146a constrains Tfh, germinal center (GC) B cell, and IgA levels in the intestine. Peyer's Patches were collected from WT C57BL/6 and miR-146a-/- mice, and flow cytometry was utilized to examine T and B cell populations within these GALT structures. Displayed are representative flow plots, percentages, and total numbers of CXCR5 ${ }^{+} \mathrm{PD}-1^{+}(\mathrm{Tfh}) \mathrm{CD} 4^{+} \mathrm{CD} 3 \mathrm{e}^{+} \mathrm{T}$ cells within the PP. All populations were first gated on lymphocytes using the FSC/SSC gate, then on CD3e $\mathrm{e}^{+} \mathrm{CD} 4^{+}$cells, followed by the PD-1 and CXCR5 gating shown a. Representative flow plots, percentages, and total numbers of $\mathrm{GL}^{+} \mathrm{FAS}^{+}(\mathrm{GC} \mathrm{B}) \mathrm{B}^{2} 20^{+} \mathrm{IgD}{ }^{\mathrm{lo}} \mathrm{B}$ cells within the $\mathrm{PP}$ are shown. All populations were first gated on lymphocytes using the FSC/SSC gate, then on $\mathrm{B} 220^{+} \mathrm{IgD}^{\mathrm{lo}}$ cells, followed by the GL7 and FAS gating shown $\mathbf{b}$. Representative flow plots and quantification of mean fluorescence intensity (MFI) of ICOS on CD3e ${ }^{+} \mathrm{CD} 4^{+} \mathrm{T}$ cells (left histogram) and Tfh cells (right histogram), measured via flow cytometry with a fluorescent antibody against ICOS. All populations were first gated on lymphocytes using the FSC/SSC gate, then on CD $3 \mathrm{e}^{+} \mathrm{CD} 4^{+}$cells, followed by PD- $1^{+}$and CXCR5 ${ }^{+}$for Tfh cells $\mathbf{c}$. Shown are representative flow plots and percentages of $\mathrm{CXCR}^{+} \mathrm{ICOS}^{+} \mathrm{CD} 4^{+} \mathrm{CD} 3 \mathrm{e}^{+} \mathrm{T}$ cells within the PP. All populations were first gated on lymphocytes using the FSC/SSC gate, then on CD3 $\mathrm{e}^{+} \mathrm{CD} 4^{+}$cells, followed by the ICOS and CXCR5 gating shown $\mathbf{d}$. Feces pellets were collected from WT and miR-146a-/- mice, weighed, and homogenized; total IgA was measured in fecal homogenates via ELISA e. $n=13$ (WT) and 14 (miR-146a-/-) (a-d), $n=8$ e. 
cells, and a previously reported role of miR-146a in Tfh function [32]. Furthermore, the percentage of CXCR5 ${ }^{+}$ Tfh cells expressing ICOS was increased in miR-146a-/mice compared with WT (Figure 4d). Consistent with an enhanced germinal center reaction, total fecal IgA levels were also elevated in miR-146a-/- compared with WT mice (Figure 4e). Tfh cells, GC B cells, and IgA have all been shown to play an important role in promoting intestinal barrier and in shaping microbial populations within the gut $[55,59-61]$. Altogether, these results indicate that miR-146a-/- mice have increased Tfh and GC $\mathrm{B}$ cells within the intestine, correlating with elevated $\mathrm{T}$ cell ICOS expression and IgA levels.

\section{miR-146a-/- mice are resistant to DSS-induced colitis}

Altered intestinal inflammatory responses and barrier function have been linked to diseases within the intestinal tract. Because our RNA-sequencing (Supplementary Figure $4 \mathrm{a}$ and $4 \mathrm{~b}$ ) and immunological data suggested that miR-146a-/- mice might be resistant to inflammatory bowel disease (IBD) and colitis, we utilized the dextran sodium sulfate (DSS) murine colitis model to examine barrier function and disease susceptibility within the intestines. This model of intestinal inflammation, which affects both the colon and small intestine, models human Ulcerative Colitis [62-64]. After 8 days of DSS treatment, WT mice lost significantly more weight than miR-146a-/- mice (Figure 5a), and miR-146a-/- colons were longer in both DSS-treated and untreated mice (Figure 5b). The net change in colon length following DSS administration was less in miR-146a-/- mice compared to controls (Supplementary Figure 6a). Upon examination of H\&E stained colonic sections by a blinded pathologist, WT colons had a complete loss of crypts and intestinal architecture, and a large infiltration of leukocytes (Figure 5e). DSS-treated miR-146a-/- colons appeared diseased, but some crypts were still in tact and inflammation and tissue damage were reduced (Figure 5f). Both WT and miR-146a-/- colons that were untreated appeared normal (Figure 5c and 5d). Altogether, WT mice showed higher histological colitis scores compared with mice lacking miR-146a (Figure 5g). Decreased expression of TNF $\alpha$ and IL-6 mRNAs within colons of miR-146a-/- DSStreated animals also indicated reduced disease severity (Supplementary Figure 6b and 6c).

In order to understand the contribution of miR-146a within hematopoietic versus non-hematopoietic cells to DSS colitis susceptibility, we performed bone marrow reconstitutions, where WT or miR-146a-/- CD45.2 $2^{+}$bone marrow was transferred to lethally irradiated WT mice carrying the CD45.1 marker. Following hematopoietic cell reconstitution, DSS was administered to bone marrow recipient animals. WT mice that received miR-146a-/- bone marrow were again more protected from DSS colitis compared with WT bone marrow recipients, as shown by weight loss differences (Figure 5 h). Flow cytometric analysis of the spleen revealed that recipient bone marrow $\left(\mathrm{CD} 45.2^{+}\right)$made up a majority of the hematopoietic cells, indicating that the reconstitution was effective (Figure 5i). These data demonstrate that the observed colitis phenotype is mediated by miR-146a within the hematopoietic compartment. Altogether, our data reveal that miR-146a decreases intestinal barrier function resulting in elevated DSS colitis severity.

Upon examination of the intestinal landscape, one cannot ignore the crosstalk between host tissues and the $10^{14}$ commensal organisms that reside in this locale [65]. Owing to the clear differences in intestinal barrier and immunological parameters between WT and miR146a-/- mice, we hypothesized that alterations to the microbiota must be taking place. To directly test this, we performed Illumina sequencing of $16 \mathrm{~s}$ rDNA extracted from fecal pellets of both genotypes to determine if there were differences in microbial populations. Both unweighted and weighted, normalized Unifrac distances demonstrated significant differences between total microbial communities in WT versus miR-146a-/- mice (Supplementary Figure 7a). Larger and more significant Unifrac distances were observed using the unweighted measure, which is more dependent upon differences in rare bacterial taxa. Alpha diversity, as measured by multiple indices, was not significantly different between WT and miR-146a-/- mice, although a larger distribution in alpha diversity was observed in the knockout group (Supplementary Figure 7b). Upon comparison of microbial taxa that varied between WT and miR-146a-/mice, statistically significant shifts at the phyla level were not observed (Supplementary Figure 7c). Altogether, these data indicate that host miR-146a plays some role in shaping the gut microbiota by regulating the magnitude of host-barrier function, albeit commensal community shifts were minor and within rare taxonomic groups.

Because miR-146a-/- mice had some alterations in gut microbiota composition compared to WT controls, we tested the direct contribution of these small community shifts to disease susceptibility. WT or miR-146a-/mouse gut microbiota was transferred to broad-spectrum antibiotic pre-treated WT recipient mice via oral gavage, and DSS colitis was induced following transfer. We observed no difference in DSS disease severity when comparing recipients having received WT or miR-146a-/microbiota. This provides evidence that the microbiota does not directly facilitate the phenotypic differences in colitis symptoms (Supplementary Figure 7d). Altogether, our data reveal that miR-146a decreases intestinal barrier function resulting in elevated DSS colitis severity, and this involves hematopoietic cells and appears to be microbiotaindependent. 

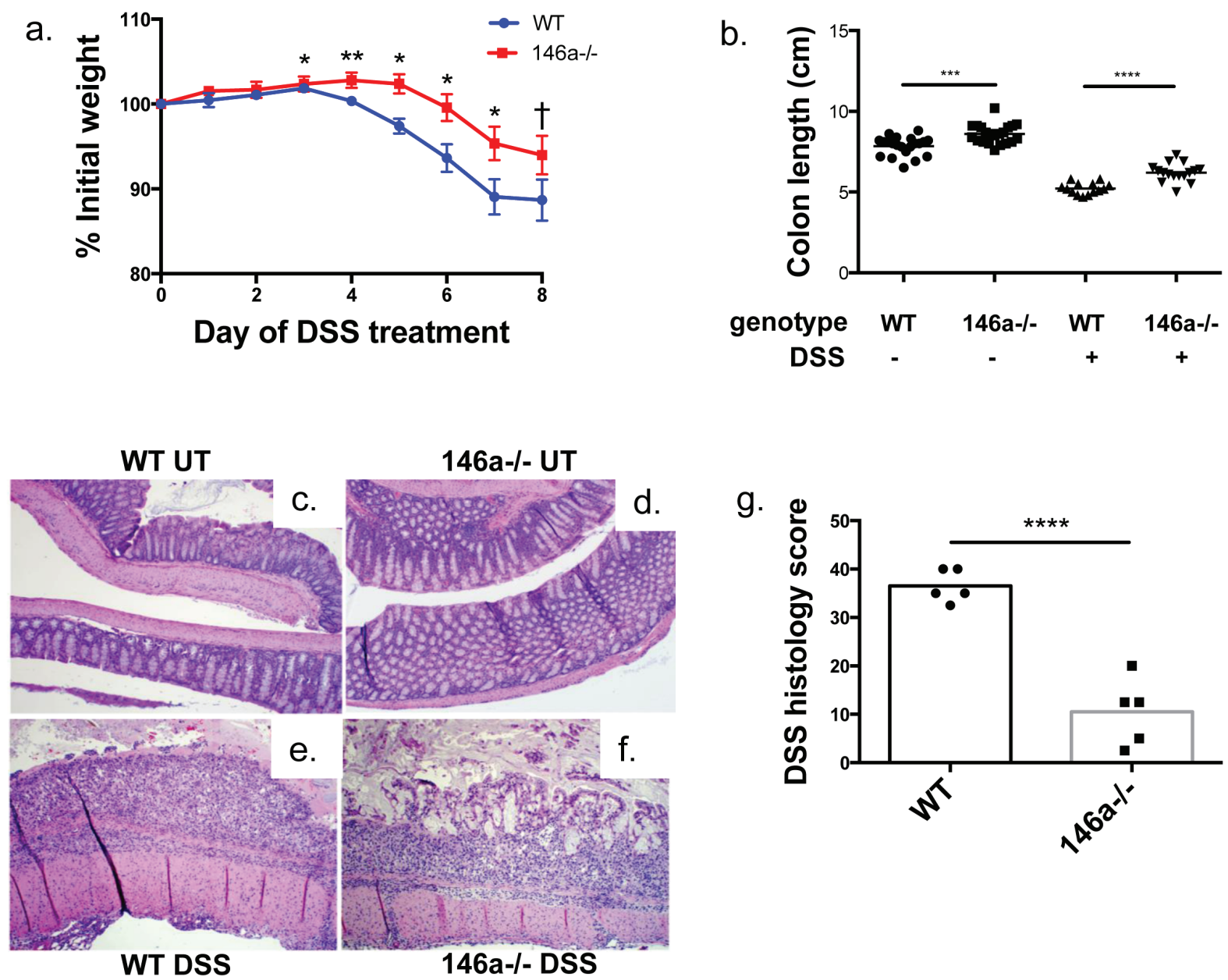

h.

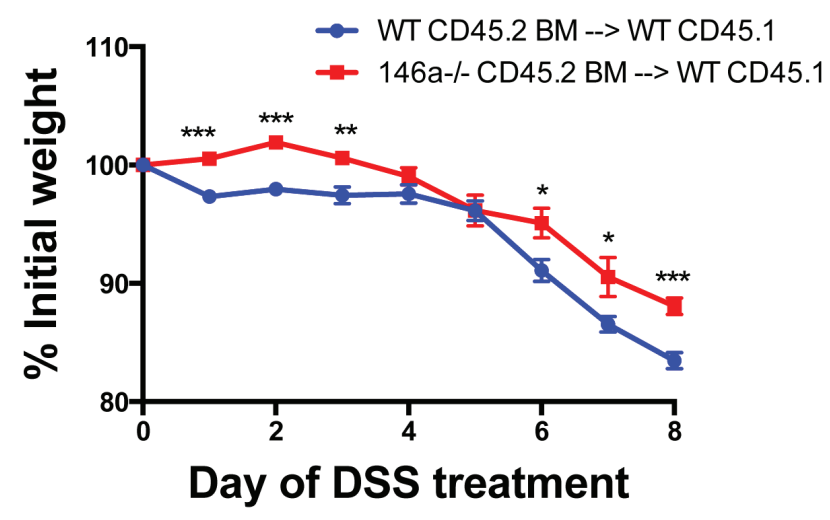

i.

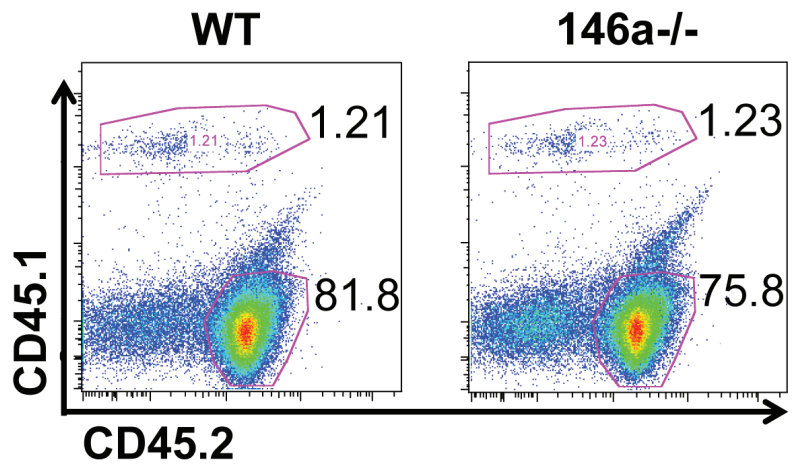

Figure 5: miR-146a-/- mice are protected from DSS-induced colitis. WT C57BL/6 and miR-146a-/- mice were treated with $3.5 \%$ dextran sodium sulfate (DSS) for eight days. Weight change of WT and miR-146a-/- mice during DSS colitis, as measured by percent initial weight a. Colon lengths of WT and miR-146a-/- mice before (left columns) and after DSS treatment (right columns) b. H\&E staining of untreated (UT) and DSS-treated WT and miR-146a-/- colonic sections, shown at 10x magnification c.-f. Histology scores of H\&E stained DSS-treated colon tissues, based on grade 3 and 4 mucosa loss, as scored by a blinded pathologist $\mathbf{g}$. Weight change during DSS colitis following bone marrow transfer of WT or miR-146a-/- CD45.2 bone marrow into lethally irradiated WT CD45.1 recipients $\mathbf{h}$. Representative flow cytometry plots showing percentages of donor (WT or miR-146a-/- CD45.2 ) and recipient (WT CD45. $1^{+}$) splenocytes following bone marrow reconstitution i. $n=16(\mathrm{a}-\mathrm{b}) ; n=5$ (c-g); $n=15$ (h-i). 


\section{miR-146a is overexpressed in patients with ulcerative colitis}

Because we found a role for miR-146a in regulating colitis in mice, ulcerative colitis (UC) patients were examined to determine if miR-146a levels correlate with intestinal disease in humans. We obtained ulcer-free colon biopsies from non-diseased individuals (normal) and UC patients. Mature miR-146a RNA levels were measured, and we found that miR-146a expression was significantly elevated in UC patients compared to healthy controls (Figure 6). These data further demonstrate correlation of miR-146a expression in human UC and CD, in which previous studies have found associations of miR-146a expression and polymorphisms with IBD type and risk [24,66-68]. Our results indicate that higher miR-146a levels correlate with UC, and further investigation may distinguish the severity of disease and/or development of colorectal cancer (CRC) as a result of UC.

\section{DISCUSSION}

Our study provides the first genetic evidence that miR-146a, a microRNA that is important in a variety of immunological contexts, is also relevant within intestinal tissues. In previous studies, miR-146a was shown to be an anti-inflammatory miRNA by repressing genes that promote pro-inflammatory signaling. In this way, loss of miR-146a results in worsened disease susceptibility and severity in most model systems [23, 27, 29, 33, 69]. Our study is unique in that loss of miR-146a resulted in a more beneficial host outcome following DSS-induced colitis. This appears to be the result of miR-146a downregulating expression of genes and cell types that fortify the intestinal barrier.

Previous work has shown that miR-146a down regulates pro-inflammatory pathways, including signaling downstream of the TLR/IL1R adaptor protein MyD88 in addition to IFN activated Stat1, in a variety of peripheral tissues[27, 31, 56]. Pathway analysis of our gene expression data set indicates that miR-146a represses these same pathways in the gut. MyD88 signaling is actually beneficial in the intestines, as MyD88-/- mice develop worsened DSS colitis [16-18, 54]. One mechanism used by TLR/MyD88 signaling to protect the gut is induction of antimicrobial peptides such as RegIII $\gamma$ [40], mucins [70], IL-18 [52], and other molecules that are produced by intestinal epithelial cells. Consistent with miR-146a repressing this pathway, miR-146a-/- mice are more protected from DSS colitis compared to control mice, and all of these TLR-MyD88 induced, host protective genes are elevated in the small intestines of miR-146a-/- mice. In addition to TLR/MyD88 signaling, we also see predicted de-repression of the IFN activated factor Stat1, a pathway that has also been shown to protect gut tissues. Taken together, miR-146a-/- mice appear to be protected from

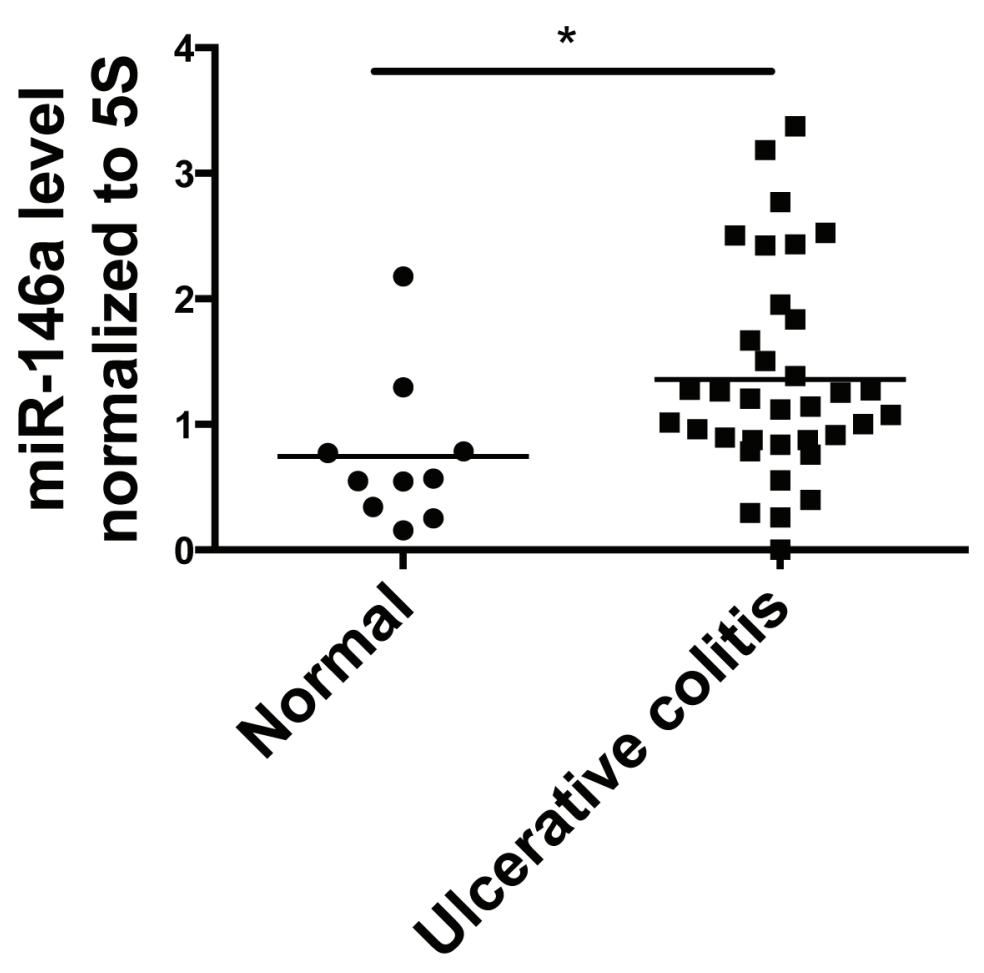

Figure 6: miR-146a expression is elevated in colon tissue from human Ulcerative Colitis (UC) patients. Colonic biopsies were collected from healthy individuals (Normal) and Ulcerative Colitis (UC) patients. qRT-PCR was used to measure levels of mature miR-146a RNA within the collected tissue, and expression was normalized to 5S rRNA. $n=10$ (normal), $n=35$ (UC). 
DSS colitis through a mechanism involving enhanced TLR/MyD88 and IFN/Stat1 signaling. However, the additional miR-146a targets identified in our RNA-Seq experiment, as well as ICOS function in Tfh cells, also appear to be involved.

We also observed enhanced GC responses in the PPs of miR-146a-/- mice, including increases in Tfh and GC $\mathrm{B}$ cells and elevated IgA levels in the intestinal lumen. This correlated with increased ICOS expression on T cells, presumably through direct miR-146a targeting of ICOS mRNA and other Tfh-related genes [32]. Interestingly, we have recently reported that $\mathrm{T}$ cell specific MyD88 signaling is critical for Tfh cell formation and downstream formation of GC B cells and IgA production [55]. Further, this pathway impacted the host microbiota through selective IgA binding to commensal populations, and this was beneficial to host intestinal health. It has been shown that miR-146a negatively regulates downstream TLR signaling pathways (e.g. TRAF6) in $\mathrm{CD} 4^{+} \mathrm{T}$ cells, and our data suggest that miR-146a acts as a negative regulator of $\mathrm{T}$ cell intrinsic TLR signaling that triggers increased GC responses, luminal IgA and intestinal health. Therefore, this appears to be an additional mechanism underlying the miR-146a-/- mouse gut phenotype.

Intestinal miR-146a expression is enriched in cells of the hematopoietic lineage, although this does not rule out the possibility that the observed low-level expression of this miRNA in CD45- cells may also be functional. Even so, we observed protection from colitis in WT mice upon bone marrow reconstitution with miR146a-/- cells, indicating that it plays a required role in the hematopoietic compartment. Future work with miR-146a conditional knockout mice will allow us to determine the relative contribution of distinct cell types to the miR-146a intestinal phenotype, including an assessment of $\mathrm{T}$ cell and IEC intrinsic roles for this miRNA.

We have found that WT and miR-146a-/- mice have different gut microbial populations, demonstrating that miR-146a plays some role in shaping commensal microbiota. Although the biological relevance of the altered populations is currently unclear, and does not appear to impact the DSS phenotype, these altered microbial populations may be playing important roles in other intestinal conditions such as Crohn's Disease and CRC. miR-146a reshaping of the microbiota might also be relevant in extra-intestinal disorders [71], such as obesity [72] and diabetes [73, 74], multiple sclerosis [75], and infections [76-78], as both miR-146a and the microbiota have been implicated in these situations.

While miR-146a-/- mice are protected from DSS colitis, a model of intestinal barrier function, the functional role of miR-146a during CRC is unknown. In fact, miR$146 \mathrm{a}$ is thought of as a tumor suppressor in many cancer settings [27]. In addition, miR-146a has also been shown to play a role in protection from ischemia/reperfusion injury [30] and may contribute to early microbial colonization in the gut [34]. Thus, the benefits of miR146a function within the gut may outweigh its adverse effects during colitis. This might explain why miR-146a has evolved to play a negative regulatory role during at least some forms of colitis.

Our study shows that miR-146a has clinical relevance within the intestine, as UC patients on average show elevated levels of this miRNA within the colon tissue. Thus, targeting miR-146a therapeutically might prove to be an effective treatment of this condition. However, one must keep in mind that using miR-146a as a therapy to treat extra-intestinal disorders may exacerbate intestinal disease. Future studies need to be done to examine the interplay of miR-146a expression within different contexts in human patients to determine how to design targeted delivery of miR-146a therapeutics. It is also possible that inhibition of miR-146a may be beneficial for some human patients with intestinal disease, but again, proper targeting to gut cells will be important

\section{MATERIALS AND METHODS}

\section{Animals}

All WT and miR-146a-/- mice are on a C57BL/6 background and were bred and housed in a specific pathogen-free mouse facility at the University of Utah, USA. WT Germ-free mice were housed in the germfree mouse facility at the University of Utah, USA. All mice were 6-8 weeks old at time of experimentation. Experimental procedures were performed with the approval of the Institutional Animal Care and Use Committee (IACUC) of University of Utah, USA.

\section{CD45 cell sorting}

WT and miR-146a-/- colons and small intestines were obtained, mesenterium was removed, and the tissues were rinsed in PBS. Intestines were cut longitudinally, cleaned of mucus and feces, and cut into fragments. Fragments were then placed in a cell dissociation solution made of calcium-free HBSS with 5mM EDTA and 10uM HEPES (colon) or $1 \mathrm{mM}$ DTT (small intestine) and incubated for 45 minutes at $37^{\circ} \mathrm{C}$. Following cell dissociation, samples were strained into $100 \mathrm{uM}$ filters and flow-through was collected and placed on ice. Intestinal fragments were then placed in a digestion mix containing calcium-free HBSS, 5\% FBS, $1 \mathrm{U} / \mathrm{mL}$ Dispase (Roche), $0.5 \mathrm{mg} / \mathrm{mL}$ Collagenase D (Roche), and $25 \mathrm{ug} /$ $\mathrm{mL}$ DNase I (Worthington) and incubated at $37^{\circ} \mathrm{C}$ for 45 minutes. Tissue was strained through a $40 \mathrm{uM}$ strainer and flowthrough was collected. Cell suspensions from the cell dissociation and digestion steps were combined and resuspended in flow cytometry buffer (HBSS, $10 \mathrm{mM}$ 
Table 1: Primer sequences

\begin{tabular}{|c|c|c|}
\hline Gene & Forward primer (5'-3') & Reverse primer (5'-3') \\
\hline Reg3b & CTGCCTTAGACCGTGCTTTC & ATAGGGCAACTTCACCTCAC \\
\hline Reg3g & TTCCTGTCCTCCATGATCAAA & CATCCACCTCTGTTGGGTTCA \\
\hline Ceacam1S & CTGGCATCGTGATTGGAGTT & CAGAAGGAGCCAGATCCG \\
\hline Ceacam1L & GCGAGATCTCACAGAGCACA & GCTGGGAATTGAAGTTCAGG \\
\hline Il18 & GCCTCAAACCTTCCAAATCA & TGGATCCATTTCCTCAAAGG \\
\hline Nos2 & CAGCTGGGCTGTACAAACCTT & CATTGGAAGTGAAGCGGTTCG \\
\hline Oas1 & CCAGGAAGAAGCCAAGCACCATC & AGGTTACTGAGCCCAAGGTCCATC \\
\hline Ido1 & GGCTTTGCTCTACCACATCCAC & TAGCCACAAGGACCCAGGG \\
\hline L32 & AAGCGAAACTGGCGGAAAC & TAACCGATGTTGGGCATCAG \\
\hline
\end{tabular}

HEPES, 2mM EDTA, 0.5\% w/v FBS). Cells were stained with CD45-FITC antibody (Biolegend) and 7-AAD viability staining solution (Biolegend). Fluorescenceactivated cell sorting was performed using the FACS Aria (BD Biosciences) gating on singlet, live (7-AAD') cells and sorting CD45 from CD45 cells. Qiazol (Qiagen) was added to WT and miR-146a-/- small intestine and colon samples containing $>10,000 \mathrm{CD}^{+} 5^{+}$or $\mathrm{CD}^{4} 5^{-}$sorted cells. RNA was extracted from sorted cells using the miRNeasy kit (Qiagen) and miR-146a expression was quantified via qPCR as described above.

\section{Gene expression analysis}

$1 \mathrm{~cm}$ pieces of distal colon and ileum of the small intestine (SI) were removed, gently cleaned to remove mucus and feces, and rinsed in PBS. The colon and SI pieces were then placed in Qiazol (Qiagen). Tissues were homogenized and RNA was extracted using the RNeasy or miRNeasy spin column kit (Qiagen) and quality was measured. Samples were prepared and sequenced at the Microarray and Genomic Analysis Core Facility at University of Utah, USA. Libraries were prepared using RiboZero treatment and sequencing was done with Illumina TruSeq Stranded RNA-seq in 50 singleend cycles. Sequences were aligned and annotated with help of the Bioinformatics Core Facility at University of Utah, USA. Pathways were examined by uploading analyzed data into the Ingenuity IPA software program and performing a core analysis on genes upregulated or downregulated by 2-fold or more, (with Phred-transformed
FDR $>10)$.

Quantitative real-time PCR (qRT-PCR) was performed using RNA prepared in the manner described above, which underwent randomly primed cDNA synthesis using qScript cDNA SuperMix (Quanta Biosciences). qRT-PCR was performed using SYBR green detection with GoTaq qPCR master mix (Promega) or LightCycler 480 SYBR Green I Master (Roche). All primers were purchased from Integrated DNA Technologies (IDT) and signals were normalized to L32. Primers sequences are listed in Table 1.

Mature miR-146a was quantified using the miRCURY LNA Universal RT microRNA PCR cDNA synthesis and SYBR Green Master Mix kits (Exiqon). microRNA levels were normalized to 5S rRNA (primer from Exiqon) and the LNA miR-146a primer was purchased from Exiqon.

\section{Lamina propria and Peyer's patch isolation/flow cytometric analysis}

WT and miR-146a-/- colons and small intestines were obtained; the entire colon was cut from the anus to the cecum and the first $20 \mathrm{~cm}$ of the small intestine beginning with the ileum was used. Mesenterium, connective tissue, and Peyer's Patches were removed; the tissues were rinsed in PBS. Intestines were cut longitudinally and mucus and feces were removed. Tissues were then cut into fragments and were then placed in a cell dissociation solution made of calcium-free HBSS (Corning) with $5 \mathrm{mM}$ EDTA and 10mM HEPES (colon) or HBSS with $5 \mathrm{mM}$ 
EDTA and $1 \mathrm{mM}$ DTT (small intestine) and incubated for 45 minutes at $37^{\circ} \mathrm{C}$. Following cell dissociation, samples were strained into $100 \mathrm{uM}$ filters and flow-through was discarded. Intestinal fragments were then placed in a digestion mix containing calcium-free HBSS with 5\% w/v FBS, $1 \mathrm{U} / \mathrm{mL}$ Dispase (Roche), $0.5 \mathrm{mg} / \mathrm{mL}$ Collagenase $\mathrm{D}$ (Roche), and $25 \mathrm{ug} / \mathrm{mL}$ DNase I (Worthington) and incubated at $37^{\circ} \mathrm{C}$ for 45 minutes. Tissue was strained through a $40 \mathrm{uM}$ strainer and flowthrough containing LP cells was collected. Cells were subjected to a $40 \%-80 \%$ Percoll gradient spin, then washed and resuspended in FACS buffer (HBSS, 10mM HEPES, 2mM EDTA, 0.5\% w/v FBS). Cells were restimulated with PMA (Sigma), ionomycin (Sigma), and Golgi plug (BD) for 4 hours, were surface stained with fluorophore-conjugated antibodies B220-FITC (Biolegend), CD11b-APC (Biolegend), CD3ePerCP Cy5.5 (Biolegend), and CD4-FITC (eBioscience) before they were fixed and permeablized overnight. Cells were washed and intracellulary stained with FoxP3APC (eBioscience), IL-10-PE (eBioscience), IFN $\gamma$-PE (eBioscience), and IL-17a-APC (eBioscience) before washing and running in a flow cytometer (LSR Fortessa, BD Biosciences).

Peyer's Patches were removed from the small intestines of WT and miR-146a-/- mice. They were gently passed through a $40 \mu \mathrm{M}$ filter in PBS in order to obtain white blood cells. Cell suspensions were then washed and resuspended in flow buffer (HBSS, 10mM HEPES, $2 \mathrm{mM}$ EDTA, $0.5 \% \mathrm{w} / \mathrm{v}$ FBS). Germinal center B cells were identified by staining with antibodies against GL7 (ebioscience), FAS (BD Pharmagen), IgD (Biolegend) and B220 (Biolegend). The Tfh cells were identified by staining with antibodies against CD3 $\varepsilon$ (eBioscience), CD4 (eBioscience), CXCR5 (ebioscience), PD-1 (Biolegend), and/or ICOS (Biolegend), and gating based on isotype or unstained controls.

\section{Microbiota analysis}

WT and miR-146a-/- mice were sacrificed; their colons were collected and cut open longitudinally. Feces was removed and flash-frozen in liquid nitrogen. Microbial DNA was extracted from feces using the PowerSoil DNA Isolation kit (MoBio). From the extracted DNA, 16S rDNA V4 region PCR amplicons were sequenced on the MiSeq platform (Illumina) using the $2 \times 250$ bp protocol yielding pair-end reads with a mean merged length of 247 bps [79]. Following sequencing, raw BCL files were retrieved from the MiSeq platform and called into fastqs by Casava v1.8.3 (Illumina). The read pairs were merged using USEARCH v7.0.1090 with the fastq_mergepairs parameters '-fastq_minovlen 20 -fastq_truncqual 5 -fastq_maxdiffs 5 -fastq_maxmergelen 350 -minhsp 8', then filtered with fastq filter to exclude sequences with more than 0.5 expected errors over the length of the merged read. Bowtie2 v2.2.1 was used to identify and remove reads mapping to the PhiX genome. Sequences were next demultiplexed based on exact barcode matches and then clustered into 97\% identity operational taxonomic units (OTUs) using the UPARSE pipeline [80]. Phylogenetic annotation of OTUs was achieved by mapping the UPARSE OTUs to the SILVA v111 database with a minimum identity of $97 \%$ [81]. The resulting OTU table representing 2,301,977 sequences in 582 OTUs was rarefied to an even depth of 21,707 reads per sample prior to calculation of alpha-diversity, betadiversity, taxonomic summaries, and related analyses in QIIME and the phyloseq R package [82-87]. Significance of categorical variables were determined using the nonparametric Kruskal-Wallis test. Correlation between two continuous variables was determined with linear regression models, where p-values indicate the probability that the slope of the regression line is zero. Principal coordinate plots employed the Monte Carlo permutation test to estimate p-values. All p-values were adjusted for multiple comparisons with the FDR algorithm.

\section{Colitis}

Dextran sodium sulfate (DSS) colitis was induced by dissolving DSS (MP Biomedicals, 36,000-50,000 $\mathrm{mw}$ ) in autoclaved water at a $3.5 \% \mathrm{w} / \mathrm{v}$ concentration. DSS water was placed in cages of WT and miR-146a-/mice, where they drank DSS water ad libitum for 8 days; water was changed to fresh DSS water on day 4. Mice were weighed daily and percent weight loss was tracked over time. Mice were sacrificed and analyzed for disease severity on day 8 , where colon length was measured, and colons were fixed in formalin for histology. For qRT-PCR of DSS-treated colon segments, colon tissue was subjected to a $\mathrm{LiCl}$ purification following $\mathrm{RNA}$ isolation to remove residual DSS [88].

\section{Microbiota transfers}

Donor microbiota was obtained by scraping mucus and feces from colons of WT and miR-146a-/- mice. Scrapings were placed in sterile PBS, centrifuged at 400G to remove debris, then resuspended and centrifuged at $8000 \mathrm{G}$ to obtain bacteria. Samples were resuspended in sterile PBS and flash frozen for gavage. Recipient mice were treated with an antibiotic cocktail of Gentamycin (Goldbio), Ampicillin (Cellgro), Neomycin Sulfate (Fisher), and Erythromycin (Fisher); each at $0.5 \mathrm{~g} / \mathrm{L}$ in drinking water for 7 days. After 7 days, drinking water was changed to regular water and 100ul of donor WT or miR-146a-/- bacteria was orally gavaged into recipient mice every day for 7 days. Following gavage, mice rested for 7 days to allow for microbiota stabilization. Finally, DSS colitis was administered in recipient mice using the methods described above. 


\section{miR-146a expression in human patients}

Colon biopsies were obtained from normal (healthy) or Ulcerative Colitis patients. Frozen biopsy samples were processed in RNAlater-ICE transition solution overnight at $-20^{\circ} \mathrm{C}$ and homogenized using Qiagen TissueRupter. Total RNA was extracted from the resultant tissue suspension using TRIzol LS reagent as per the manufacturer's instructions. qPCR was performed to assay expression levels of mature miR-146a using the methods described above.

\section{Statistics}

A Student's t-test was utilized to determine significant $\mathrm{p}$-values when comparing two groups, unless otherwise noted. $\dagger \leq 0.12 ; * \mathrm{p} \leq 0.05 ; * * \mathrm{p} \leq 0.01$; *** $\mathrm{p} \leq 0.001 ; * * * * \mathrm{p} \leq 0.0001$. For $\mathrm{p}$-values during DSS colitis, individual t-tests were performed at each time point. Outliers from experiments were removed using the Graphpad Prism 6 "identify outliers" statistical function. See "microbiota analysis" and "gene expression analysis" sections for explanation of statistics in those experiments.

\section{ACKNOWLEDGMENTS}

Thank you to all members of the Ryan O'Connell Lab and June Round Lab who assisted with experiments and gave advice on this project. Many thanks to the David Baltimore lab, who originally provided the miR-146a-/mice. Thank you to the Microarray and Genomic Analysis Core Facility for performing the RNA-seq and to Darren Ames and the Bioinformatics Core Facility for analyzing the sequencing data. Thanks to Erin Bake and the University of Utah Animal Facility, who assisted with care of the mice. Many thanks to Ginger A. Metcalf, Donna M. Muzny, and Richard A. Gibbs at the Human Genome Sequencing Center at Baylor College of Medicine for overseeing the sequencing of the microbiome component of this study.

\section{CONFLICTS OF INTEREST}

\author{
We declare that there is no conflict of interest at this \\ time.
}

\section{Editorial note}

This paper has been accepted based in part on peerreview conducted by another journal and the authors' response and revisions as well as expedited peer-review in Oncotarget.

\section{REFERENCES}

1. Round JL, Mazmanian SK. The gut microbiota shapes intestinal immune responses during health and disease. Nat Rev Immunol 2009; 9:313-323.

2. Hooper L V, Macpherson AJ. Immune adaptations that maintain homeostasis with the intestinal microbiota. Nat Rev Immunol 2010; 10:159-169.

3. Petersen C, Round JL. Defining dysbiosis and its influence on host immunity and disease. Cell Microbiol 2014; 16:1024-1033.

4. Abraham C, Cho JH. Inflammatory bowel disease. N Engl J Med 2009; 361:2066-2078.

5. Bollrath J, Powrie FM. Controlling the frontier: Regulatory T-cells and intestinal homeostasis. Semin Immunol 2013; 25:352-357.

6. Peterson D a, McNulty NP, Guruge JL, Gordon JI. IgA response to symbiotic bacteria as a mediator of gut homeostasis. Cell Host Microbe 2007; 2:328-39.

7. Ahmad S. Antibody responses: IgA - peacemaker in the gut. Nat Rev Immunol 2008; 8:6-7.

8. Kato LM, Kawamoto S, Maruya M, Fagarasan S. Gut $\mathrm{TFH}$ and IgA: key players for regulation of bacterial communities and immune homeostasis. Immunol Cell Biol 2014; 92:49-56.

9. Neurath MF. Cytokines in inflammatory bowel disease. Nat Rev Immunol 2014; 14:329-42.

10. Shale M, Schiering C, Powrie F. CD4+ T-cell subsets in intestinal inflammation. Immunol Rev 2013; 252:164-182.

11. Maloy KJ, Kullberg MC. IL-23 and Th17 cytokines in intestinal homeostasis. Mucosal Immunol 2008; 1:339-349.

12. Cao AT, Yao S, Gong B, Elson CO, Cong Y. Th17 cells upregulate polymeric Ig receptor and intestinal $\operatorname{IgA}$ and contribute to intestinal homeostasis. J Immunol 2012; 189:4666-73.

13. Peterson LW, Artis D. Intestinal epithelial cells: regulators of barrier function and immune homeostasis. Nat Rev Immunol 2014; 14:141-53.

14. Artis D. Epithelial-cell recognition of commensal bacteria and maintenance of immune homeostasis in the gut. Nat Rev Immunol 2008; 8:411-20.

15. Reynolds JM, Dong C. Toll-like receptor regulation of effector T lymphocyte function. Trends Immunol 2013; 34:511-519.

16. Rakoff-Nahoum S, Paglino J, Eslami-Varzaneh F, Edberg $\mathrm{S}$, Medzhitov R. Recognition of commensal microflora by toll-like receptors is required for intestinal homeostasis. Cell 2004; 118:229-41.

17. Frantz AL, Rogier EW, Weber CR, Shen L, Cohen DA, Fenton LA, Bruno ME, Kaetzel CS. Targeted deletion of MyD88 in intestinal epithelial cells results in compromised antibacterial immunity associated with downregulation of polymeric immunoglobulin receptor, mucin-2, and 
antibacterial peptides. Mucosal Immunol 2012; 5:501-512.

18. Kirkland D, Benson A, Mirpuri J, Pifer R, Hou B, DeFranco AL, Yarovinsky F. B Cell-Intrinsic MyD88 Signaling Prevents the Lethal Dissemination of Commensal Bacteria during Colonic Damage. Immunity 2012; 36:228-238.

19. Atreya I, Atreya R, Neurath MF. NF-kappaB in inflammatory bowel disease. J Intern Med 2008; 263:591596.

20. O'Connell RM, Rao DS, Baltimore D. microRNA regulation of inflammatory responses. Annu Rev Immunol 2012; 30:295-312.

21. Baltimore D, Boldin MP, O’Connell RM, Rao DS, Taganov KD. MicroRNAs: new regulators of immune cell development and function. Nat Immunol 2008; 9:839-45.

22. O'Connell RM, Rao DS, Chaudhuri A a, Baltimore D. Physiological and pathological roles for microRNAs in the immune system. Nat Rev Immunol 2010; 10:111-22.

23. Zhao JL, Rao DS, Boldin MP, Taganov KD, O'Connell RM, Baltimore D. NF-kappaB dysregulation in microRNA146a-deficient mice drives the development of myeloid malignancies. Proc Natl Acad Sci U S A 2011; 108:91849189.

24. Runtsch MC, Round JL, OConnell RM. MicroRNAs and the regulation of intestinal homeostasis. Front Genet 2014; $5: 1-10$

25. Chivukula RR, Shi G, Acharya A, Mills EW, Zeitels LR, Anandam JL, Abdelnaby A a, Balch GC, Mansour JC, Yopp AC, Maitra A, Mendell JT. An essential mesenchymal function for miR-143/145 in intestinal epithelial regeneration. Cell 2014; 157:1104-16.

26. Taganov KD, Boldin MP, Chang K-J, Baltimore D. NFkappaB-dependent induction of microRNA miR-146, an inhibitor targeted to signaling proteins of innate immune responses. Proc Natl Acad Sci U S A 2006; 103:1248112486.

27. Boldin MP, Taganov KD, Rao DS, Yang L, Zhao JL, Kalwani M, Garcia-Flores Y, Luong M, Devrekanli A, Xu $\mathrm{J}$, Sun G, Tay J, et al. miR-146a is a significant brake on autoimmunity, myeloproliferation, and cancer in mice. $\mathrm{J}$ Exp Med 2011; 208:1189-1201.

28. Yang L, Boldin MP, Yu Y, Liu CS, Ea CK, Ramakrishnan P, Taganov KD, Zhao JL, Baltimore D. miR-146a controls the resolution of T cell responses in mice. J Exp Med 2012; 209:1655-1670.

29. Zhao JL, Rao DS, O'Connell RM, Garcia-Flores Y, Baltimore D. MicroRNA-146a acts as a guardian of the quality and longevity of hematopoietic stem cells in mice. Elife 2013; 2:e0537.

30. Chassin C, Hempel C, Stockinger S, Dupont A, Kübler JF, Wedemeyer J, Vandewalle A, Hornef MW. MicroRNA146a-mediated downregulation of IRAK1 protects mouse and human small intestine against ischemia/reperfusion injury. EMBO Mol Med 2012; 4:1308-19.

31. Lu LF, Boldin MP, Chaudhry A, Lin LL, Taganov KD,
Hanada T, Yoshimura A, Baltimore D, Rudensky AY. Function of miR-146a in Controlling Treg Cell-Mediated Regulation of Th1 Responses. Cell 2010; 142:914-929.

32. Pratama A, Srivastava M, Williams NJ, Papa I, Lee SK, Dinh XT, Hutloff A, Jordan M a., Zhao JL, Casellas R, Athanasopoulos V, Vinuesa CG. MicroRNA-146a regulates ICOS-ICOSL signalling to limit accumulation of $\mathrm{T}$ follicular helper cells and germinal centres. Nat Commun 2015; 6:6436.

33. Lochhead RB, Ma Y, Zachary JF, Baltimore D, Zhao JL, Weis JH, O'Connell RM, Weis JJ. MicroRNA-146a Provides Feedback Regulation of Lyme Arthritis but Not Carditis during Infection with Borrelia burgdorferi. PLoS Pathog 2014; 10.

34. Chassin C, Kocur M, Pott J, Duerr CU, Gütle D, Lotz M, Hornef MW. MiR-146a mediates protective innate immune tolerance in the neonate intestine. Cell Host Microbe 2010; 8:358-368.

35. Ghorpade DS, Sinha AY, Holla S, Singh V, Balaji KN. NOD2-nitric oxide-responsive microRNA-146a activates Sonic hedgehog signaling to orchestrate inflammatory responses in murine model of inflammatory bowel disease. J Biol Chem 2013; 288:33037-33048.

36. Rusca N, Monticelli S. MiR-146a in Immunity and Disease. Mol Biol Int 2011; 2011:437301.

37. Cash HL, Whitham C V, Behrendt CL, Hooper L V. Symbiotic bacteria direct expression of an intestinal bactericidal lectin. Science 2006; 313:1126-1130.

38. Brandl K, Plitas G, Schnabl B, DeMatteo RP, Pamer EG. MyD88-mediated signals induce the bactericidal lectin RegIII gamma and protect mice against intestinal Listeria monocytogenes infection. J Exp Med 2007; 204:1891-1900.

39. Kolls JK, McCray PB, Chan YR. Cytokine-mediated regulation of antimicrobial proteins. Nat Rev Immunol 2008; 8:829-835.

40. Vaishnava S, Yamamoto M, Severson KM, Ruhn K a, Yu X, Koren O, Ley R, Wakeland EK, Hooper L V. The antibacterial lectin RegIIIgamma promotes the spatial segregation of microbiota and host in the intestine. Science 2011; 334:255-8.

41. Uhlar CM, Whitehead AS. Serum amyloid A, the major vertebrate acute-phase reactant. Eur J Biochem 1999; 265:501-523.

42. Eckhardt ERM, Witta J, Zhong J, Arsenescu R, Arsenescu V, Wang Y, Ghoshal S, de Beer MC, de Beer FC, de Villiers WJS. Intestinal epithelial serum amyloid A modulates bacterial growth in vitro and pro-inflammatory responses in mouse experimental colitis. BMC Gastroenterol 2010; 10:133.

43. Kim YS, Ho SB. Intestinal goblet cells and mucins in health and disease: Recent insights and progress. Curr Gastroenterol Rep 2010; 12:319-330.

44. Cho H, Kelsall BL. The role of type I interferons in intestinal infection, homeostasis, and inflammation. 
Immunol Rev 2014; 260:145-167.

45. Katakura K, Lee J, Rachmilewitz D, Li G, Eckmann L, Raz E. Toll-like receptor 9-induced type I IFN protects mice from experimental colitis. J Clin Invest 2005; 115:695-702.

46. Long TM, Nisa S, Donnenberg MS, Hassel BA. Enteropathogenic Escherichia coli inhibits type I interferonand RNase L-mediated host defense to disrupt intestinal epithelial cell Barrier function. Infect Immun 2014; 82:2802-2814.

47. Roda G, Dahan S, Mezzanotte L, Caponi A, Roth-Walter F, Pinn D, Mayer L. Defect in CEACAM family member expression in Crohn's disease IECS is regulated by the transcription factor SOX9. Inflamm Bowel Dis 2009; 15:1775-1783.

48. Chen L, Chen Z, Baker K, Halvorsen EM, Pires da Cunha A, Flak MB, Gerber G, Huang YH, Hosomi S, Arthur JC, Dery KJ, Nagaishi T, et al. The Short Isoform of the CEACAM1 Receptor in Intestinal $\mathrm{T}$ Cells Regulates Mucosal Immunity and Homeostasis via Tfh Cell Induction. Immunity 2012; 37:930-946.

49. Lei Z, Maeda T, Tamura A, Nakamura T, Yamazaki Y, Shiratori H, Yashiro K, Tsukita S, Hamada H. EpCAM contributes to formation of functional tight junction in the intestinal epithelium by recruiting claudin proteins. Dev Biol 2012; 371:136-145.

50. Ulluwishewa D, Anderson RC, McNabb WC, Moughan PJ, Wells JM, Roy NC. Regulation of tight junction permeability by intestinal bacteria and dietary components. J Nutr 2011; 141:769-776.

51. Siegmund B. Interleukin-18 in Intestinal Inflammation: Friend and Foe? Immunity 2010; 32:300-302.

52. Zaki MH, Boyd KL, Vogel P, Kastan MB, Lamkanfi M, Kanneganti TD. The NLRP3 Inflammasome Protects against Loss of Epithelial Integrity and Mortality during Experimental Colitis. Immunity 2010; 32:379-391.

53. Ciorba MA, Bettonville EE, McDonald KG, Metz R, Prendergast GC, Newberry RD, Stenson WF. Induction of IDO-1 by immunostimulatory DNA limits severity of experimental colitis. J Immunol 2010; 184:3907-3916.

54. Brandl K, Sun L, Neppl C, Siggs OM, Le Gall SM, Tomisato W, Li X, Du X, Maennel DN, Blobel CP, Beutler B. MyD88 signaling in nonhematopoietic cells protects mice against induced colitis by regulating specific EGF receptor ligands. Proc Natl Acad Sci U S A 2010; 107:19967-19972.

55. Kubinak JL, Petersen C, Stephens WZ, Soto R, Bake E, O'Connell RM, Round JL. MyD88 Signaling in T Cells Directs IgA-Mediated Control of the Microbiota to Promote Health. Cell Host Microbe 2015; 17:153-163.

56. Hu R, Kagele DA, Huffaker TB, Runtsch MC, Alexander M, Liu J, Bake E, Su W, Williams MA, Rao DS, Möller T, Garden GA, et al. miR-155 Promotes T Follicular Helper Cell Accumulation during Chronic, Low-Grade Inflammation. Immunity 2014; 41:605-619.
57. Crotty S. Follicular helper CD4 T cells (TFH). Annu Rev Immunol 2011; 29:621-663.

58. Choi YS, Kageyama R, Eto D, Escobar TC, Johnston RJ, Monticelli L, Lao C, Crotty S. ICOS Receptor Instructs T Follicular Helper Cell versus Effector Cell Differentiation via Induction of the Transcriptional Repressor Bcl6. Immunity 2011; 34:932-946.

59. Pabst $\mathrm{O}$. New concepts in the generation and functions of IgA. Nat Rev Immunol 2012.

60. Wei M, Shinkura R, Doi Y, Maruya M, Fagarasan S, Honjo T. Mice carrying a knock-in mutation of Aicda resulting in a defect in somatic hypermutation have impaired gut homeostasis and compromised mucosal defense. Nat Immunol 2011; 12:264-270.

61. Barone F, Vossenkamper A, Boursier L, Su W, Watson A, John S, Dunn-Walters DK, Fields P, Wijetilleka S, Edgeworth JD, Spencer J. IgA-producing plasma cells originate from germinal centers that are induced by B-cell receptor engagement in humans. Gastroenterology 2011; 140:947-956.

62. Yazbeck R, Howarth GS, Butler RN, Geier MS, Abbott CA. Biochemical and histological changes in the small intestine of mice with dextran sulfate sodium colitis. J Cell Physiol 2011; 226:3219-3224.

63. Rose WA, Sakamoto K, Leifer CA. Multifunctional role of dextran sulfate sodium for in vivo modeling of intestinal diseases. BMC Immunol 2012; 13:41.

64. Okayasu I, Hatakeyama S, Yamada M. A novel method in the induction of reliable experimental acute and chronic ulcerative colitis in mice. Gastroenterology 1990; 98:694702.

65. Savage DC. Microbial ecology of the gastrointestinal tract. Annu Rev Microbiol 1977; 31:107-133.

66. Gazouli M, Papaconstantinou I, Stamatis K, Vaiopoulou A, Zeglinas C, Vassiliou I, Giokas G, Tzathas C. Association Study of Genetic Variants in miRNAs in Patients with Inflammatory Bowel Disease: Preliminary Results. Dig Dis Sci 2013; 58:2324-8.

67. Lin J, Welker NC, Zhao Z, Li Y, Zhang J, Reuss S a, Zhang $\mathrm{X}$, Lee H, Liu Y, Bronner MP. Novel specific microRNA biomarkers in idiopathic inflammatory bowel disease unrelated to disease activity. Mod Pathol 2014; 27:602-8.

68. Schaefer JS, Attumi T, Opekun AR, Abraham B, Hou J, Shelby H, Graham DY, Streckfus C, Klein JR. MicroRNA signatures differentiate Crohn's disease from ulcerative colitis. BMC Immunol 2015; 16:1-13.

69. Yang L, Boldin MP, Yu Y, Liu CS, Ea C-K, Ramakrishnan P, Taganov KD, Zhao JL, Baltimore D. miR-146a controls the resolution of T cell responses in mice. J Exp Med 2012; 209:1655-1670.

70. Moncada DM, Kammanadiminti SJ, Chadee K. Mucin and Toll-like receptors in host defense against intestinal parasites. Trends Parasitol 2003; 19:305-311.

71. Kamada N, Seo S-U, Chen GY, Núñez G. Role of the gut 
microbiota in immunity and inflammatory disease. Nat Rev Immunol 2013; 13:321-35.

72. Turnbaugh PJ, Ley RE, Mahowald MA, Magrini V, Mardis ER, Gordon JI. An obesity-associated gut microbiome with increased capacity for energy harvest. Nature 2006; 444:1027-31.

73. Kemppainen KM, Ardissone AN, Davis-Richardson AG, Fagen JR, Gano KA, León-Novelo LG, Vehik K, Casella G, Simell O, Ziegler AG, Rewers MJ, Lernmark Å, et al. Early Childhood Gut Microbiomes Show Strong Geographic Differences Among Subjects at High Risk for Type 1 Diabetes: Figure 1. Diabetes Care 2015; 38:329-332.

74. Giongo A, Gano KA, Crabb DB, Mukherjee N, Novelo LL, Casella G, Drew JC, Ilonen J, Knip M, Hyöty H, Veijola R, Simell T, et al. Toward defining the autoimmune microbiome for type 1 diabetes. ISME J 2011; 5:82-91.

75. Cantarel BL, Waubant E, Chehoud C, Kuczynski J, Desantis TZ, Warrington J, Venkatesan A, Fraser CM., Mowry EM. Gut Microbiota in Multiple Sclerosis : Possible Influence of Immunomodulators. J Investig Med 2015; 63:1-6.

76. Schubert AM, Rogers MAM, Ring C, Mogle J, Petrosino JP, Young VB, Aronoff DM, Schloss PD. Microbiome Data Distinguish Patients with Clostridium difficile Infection and Non- C . difficile -Associated Diarrhea from Healthy. MBio 2014; 5:1-9.

77. Garrett WS, Lord GM, Punit S, Lugo-Villarino G, Mazmanian SK, Ito S, Glickman JN, Glimcher LH. Communicable Ulcerative Colitis Induced by T-bet Deficiency in the Innate Immune System. Cell 2007; 131:33-45.

78. Saulnier DM, Riehle K, Mistretta T-A, Diaz M-A, Mandal D, Raza S, Weidler EM, Qin X, Coarfa C, Milosavljevic A, Petrosino JF, Highlander S, et al. Gastrointestinal microbiome signatures of pediatric patients with irritable bowel syndrome. Gastroenterology 2011; 141:1782-91.

79. Caporaso JG, Lauber CL, Walters W a, Berg-Lyons D, Huntley J, Fierer N, Owens SM, Betley J, Fraser L, Bauer M, Gormley N, Gilbert J a, et al. Ultra-high-throughput microbial community analysis on the Illumina HiSeq and MiSeq platforms. ISME J 2012; 6:1621-1624.

80. Edgar RC. UPARSE: highly accurate OTU sequences from microbial amplicon reads. Nat Methods 2013; 10:996-8.

81. Quast C, Pruesse E, Yilmaz P, Gerken J, Schweer T, Yarza P, Peplies J, Glöckner FO. The SILVA ribosomal RNA gene database project: Improved data processing and webbased tools. Nucleic Acids Res 2013; 41:590-596.

82. Chao A, Chazdon RL, Colwell RK, Shen TJ. Abundancebased similarity indices and their estimation when there are unseen species in samples. Biometrics 2006; 62:361-371.

83. Shannon CE. A mathematical theory of communication. Bell Syst Tech J 1948; 27:379-423.

84. Lozupone C, Hamady M, Knight R. UniFrac--an online tool for comparing microbial community diversity in a phylogenetic context. BMC Bioinformatics 2006; 7:371.
85. R Development Core Team R. R: A Language and Environment for Statistical Computing. R Found Stat Comput 2014; 1:409.

86. McMurdie PJ, Holmes S. Phyloseq: An R Package for Reproducible Interactive Analysis and Graphics of Microbiome Census Data. PLoS One 2013; 8 .

87. Caporaso JG, Kuczynski J, Stombaugh J, Bittinger K, Bushman FD, Costello EK, Fierer N, Peña AG, Goodrich JK, Gordon JI, Huttley G a, Kelley ST, et al. correspondence QIIME allows analysis of high- throughput community sequencing data Intensity normalization improves color calling in SOLiD sequencing. Nat Publ Gr 2010; 7:335-336.

88. Viennois E, Chen F, Laroui H, Baker MT, Merlin D. Dextran sodium sulfate inhibits the activities of both polymerase and reverse transcriptase: lithium chloride purification, a rapid and efficient technique to purify RNA. BMC Res Notes 2013; 6:360. 